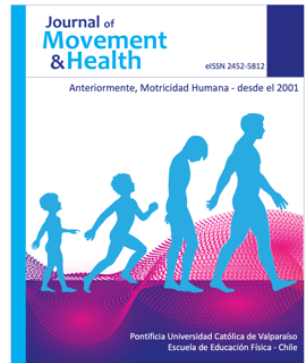

eISSN: $2452-5812$

http://jmh.pucv.cl/

Recibido: $16 / 05 / 2021$

Aceptado: $17 / 05 / 2021$

Disponible: $19 / 05 / 2021$

Publicado: 01/01/2022

\title{
Editorial
}

\section{Active transport to school as a preventive policy in the COVID-19 pandemic}

El desplazamiento activo a la escuela como política preventiva en la pandemia COVID-19

Villa-González, E ${ }^{1}$; Barranco-Ruiz, $\mathbf{Y}^{1}$; Chillón, $\mathbf{P}^{2}$

\section{Corresponding author}

Emilio Villa-González

PROFITH "PROmoting FITness and Health through physical activity" Research Group, Department of Physical Education and Sports, Faculty of Education and Sport Sciences, Sport and Health University Research Institute (iMUDS), University of Granada, Melilla 52071, Spain.

evilla@ugr.es

\section{Key Points}

- The Coronavirus disease 2019 (COVID-19) pandemic has restricted the physical activity of people of all ages worldwide, especially in young people.

- Create healthy measures to control COVID-19 spreading, such as promoting active transport as cycling and walking, may represent a public health opportunity.

- The promotion of active transport to/from school has not been sufficiently promoted during COVID-19 times.

- Active school transport is a clear promising strategy for young people to contribute to minimizing COVID-19 consequences because it can easily respect physical distancing, occurs outdoors, promotes healthy behaviors, increases environmental engagement, and decreases pollution through reduced automobile use.

Currently, coronavirus disease 2019 (COVID-19) is a serious global public health problem and was declared a pandemic by the World Health Organization (WHO) on 11 March 2020. Recent data from Johns Hopkins University reported about 162 million confirmed cases and 3.3 million deaths worldwide (15 ${ }^{\text {th }}$ May 2021). The modes of transmission of COVID-19 are direct inhalation of infected expired droplets and direct contact with surfaces and fomites soiled by infected respiratory secretions ${ }^{1}$. Clinical symptoms are similar to other acute respiratory viral infections and include fever, cough, sore throat, breathlessness, fatigue, and malaise. According to current data, children appear to have less severe COVID-19-related symptoms, lower frequency of infection, and reduced spread ${ }^{2}$.

Intense research efforts focus on identifying effective therapies and vaccines; however, in the meantime, to contain spreading and prevent overburdening healthcare systems, the most effective declared strategy is contact tracing, and physical isolation measures ${ }^{3}$. Data derived from COVID-19-related confinement indicated that physical distancing and self-isolation strongly adversely impacted peoples' lives, affecting particular eating behaviors ${ }^{4}$, daily physical activity (PA) $)^{5-7}$, and psychosocial health ${ }^{8}$.

PA in young people is essential for healthy growth and development; physical benefits include improved musculoskeletal and cardiovascular health and healthy body weight, whereas psychological benefits include managing anxiety and building self-esteem, which are important for children's psychosocial development ${ }^{9}$. The WHO recommends that children and adolescents aged 5-17 years should engage in an average of 60 minutes of moderate-to-vigorous intensity PA a day (i.e., an average of $420 \mathrm{~min} /$ week) to reduce the major risk factors for non-communicable disease ${ }^{10}$. Unfortunately, in the pre-pandemic period, only 2 out of 10 youth worldwide accumulate the recommended daily PA ${ }^{11}$. The COVID-19 
pandemic has restricted PA in people of all ages around the world ${ }^{12}$, due to policy measures established to control the COVID-19 spread (e.g., "stay-at-home" recommendations/orders, lockdowns, avoid mass gatherings). Worryingly, the decrease in PA has been very marked in young people, who are playing less outside than before the COVID-19 outbreak $^{6,13}$. A natural experimental longitudinal study ${ }^{14}$ among children and adolescents (6-17 years) conducted in five schools of Shanghai (China) found that the median time spent in PA decreased drastically, from an average of $540 \mathrm{~min} /$ week (before the pandemic) to $105 \mathrm{~min} /$ week (during the pandemic). In addition, during the pandemic, the prevalence of physically inactive students increased from $21.3 \%$ to $65.6 \%{ }^{14}$.

Recent reports suggest that measures to control the spread of COVID-19, including "stay-at-home" recommendations, respecting physical distancing, and embracing the outdoors, might in fact, represent new public health opportunities in other ways, such as an increase in commuting by cycling and walking instead of motorized transportation ${ }^{15}$. Indeed, Greenpeace, in their 'Manifesto for a Green Recovery' postCOVID, called on politicians and policymakers to 'fundamentally redesign urban transport to prioritize walking and cycling, improving public health, and delivering clean air' ${ }^{16}$.

Consistent evidence shows that children and adolescents who engage in active modes of transport to/from school (AST) are more physically active than those who travel by motorized vehicles ${ }^{17}$. Cycling to and from school can also increase cardiovascular fitness and is associated with a better cardiometabolic health profile ${ }^{17}$. Furthermore, the active transport behaviors reduce pollution, which may attenuate exacerbation of respiratory diseases, and promote a healthy respiratory system. Currently, active transportations seem to be promising healthy behaviour strategies for young people to reduce COVID-19 transmission and consequences. AST allows children and youth to a) respect physical distancing recommendations while avoiding more crowded places such as public transportation, b) embrace the outdoors avoiding indoor modes of transportation, and c) young people can perform it on their own without adult supervision (i.e., independent mobility) avoiding unnecessary exposures.

A recent review demonstrated the ineffectiveness of school closures as a COVID-19 containment strategy ${ }^{18}$, and consequently, a global decision was made to allow children back to school, where the WHO provided considerations for school-related public health measures in the context of COVID-19 ${ }^{19}$. However, actions were focused on public and private transportation measures, and there were no specific recommendations for AST promotion, which is the most healthy and sustainable mode of transportation.

Promoting AST should be a priority COVID-19 containment strategy focusing on school policies (e.g., avoid crowded school entrances associated with bus arrivals, reduce the proximity of private vehicles and provide safe bike parking) and urban city policies (an expansion in outdoor green spaces, bike lanes, pedestrian-centric streets and improvements in the urban environment around the school). The promotion of AST should be embraced as a call to action to encourage the implementation of strategies to incentivize these behaviors (respecting local public health COVID-19 guidelines) to; 1) prevent non-communicable diseases promoted through the physical inactivity of young people now and in the post-COVID period; and 2) prevent further spread of the virus among the population to reduce the COVID-19 mortality. Figure 1 presents a summary of AST benefits as well as school and city policies in the in the COVID-19 pandemic.

\section{Conclusion}

AST is a responsible and sustainable transport strategy respecting physical distancing, embracing the outdoors, promoting healthy behaviors, increasing environmental engagement while decreasing pollution. It should be promoted to prevent COVID-19 spreading in the population and collaterally contribute to physical health. Detailed surveillance will be needed to confirm the safety and benefits of this approach. 


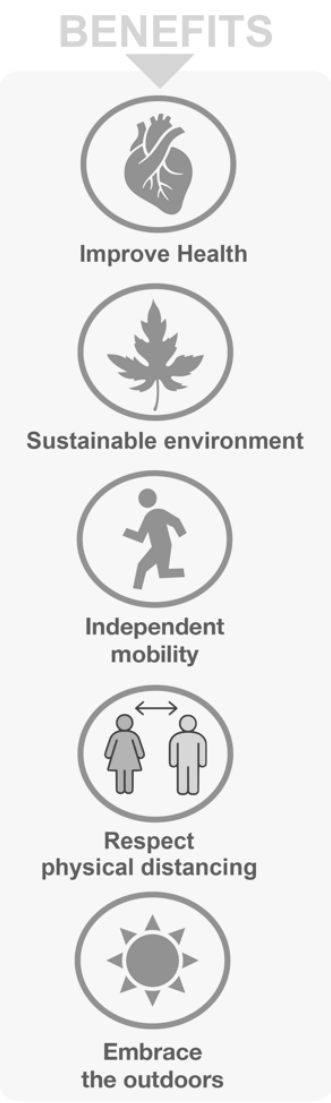

\section{Active commuting to school \\ in the COVID-19 pandemic}

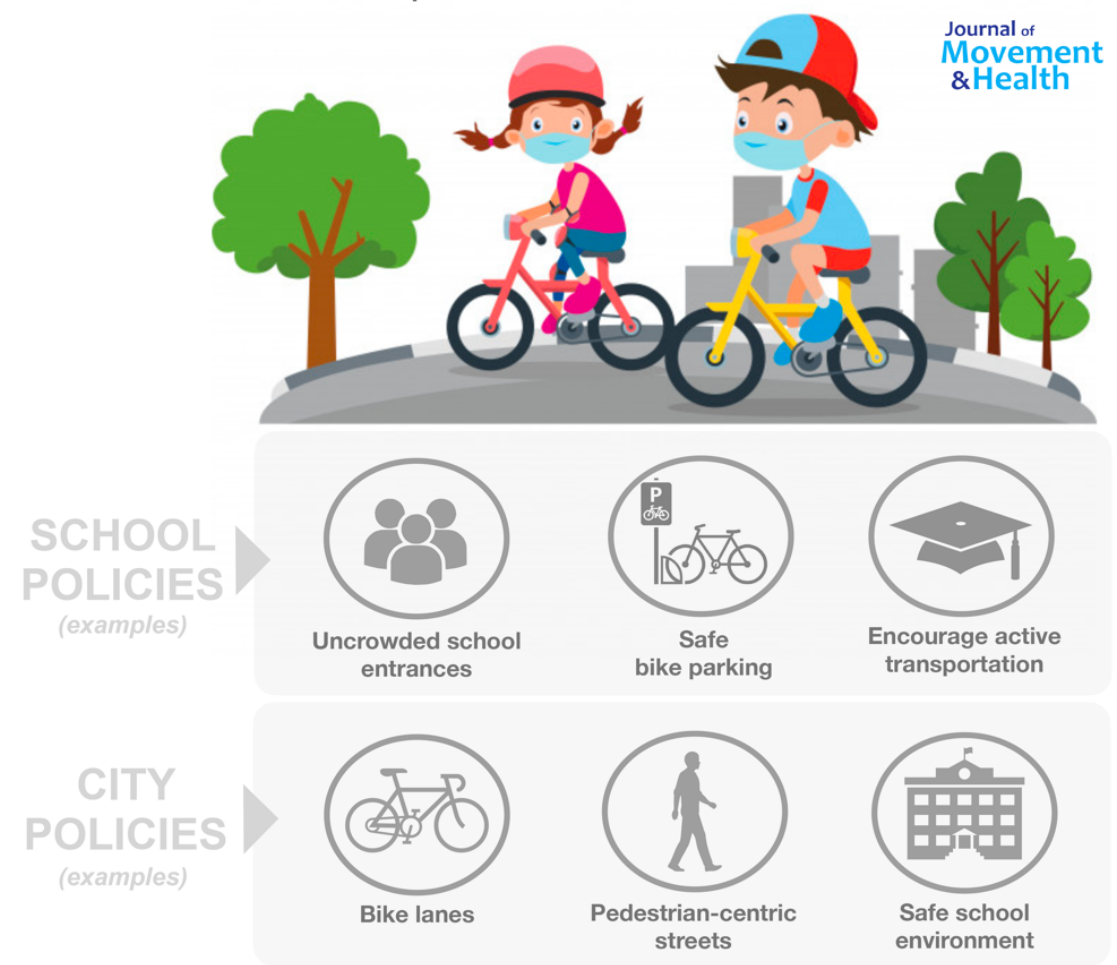

Figure 1. AST benefits, school and city policies in the in the COVID-19 pandemic.

\section{References}

1. Van Doremalen N, Bushmaker T, Morris DH, Holbrook MG, Gamble A, Williamson BN. \& LloydSmith, JO. Aerosol and surface stability of SARS-CoV-2 as compared with SARS-CoV-1. N Engl J Med. 2020;16(382(16)):1564-1567. DOI: 10.1056/NEJMc2004973

2. Munro APS, Faust SN. Children are not COVID-19 super spreaders: time to go back to school. Arch Dis Child. 2020;105(7):618-619. DOI: 10.1097/QCO.0000000000000690

3. Gallo LA, Gallo TF, Young SL, Moritz KM, Akison LK. The impact of isolation measures due to COVID-19 on energy intake and physical activity levels in Australian university students. Nutrients. 2020;23(12(6)):1865. DOI: 10.3390/nu12061865

4. Di Renzo L, Gualtieri P, Pivari F, et al. Eating habits and lifestyle changes during COVID-19 lockdown: an Italian survey. $J$ Transl Med. 2020;18(1):1-15. doi: 10.1186/s12967-020-02399-5

5. Chulvi-Medrano I, Villa-González E, Rebullido TR, Faigenbaum AD. The impact of COVID-19 quarantine on youth: from physical inactivity to pediatric depreobesity. Journal of Movement \& Health 2021;18(1). DOI: 10.5027/jmh-Vol18-Issue1(2021)art100.

6. Moore SA, Faulkner G, Rhodes RE, et al. Impact of the COVID-19 virus outbreak on movement and play behaviours of Canadian children and youth: a national survey. Int J Behav Nutr Phys Act. 2020;17(1):1-11. DOI: 10.1186/s12966-020-00987-8 
DOI: https://doi.org/10.5027/jmh-Vol19-Issue1(2022)art129

7. Shahidi SH, Stewart Williams J, Hassani F. Physical activity during COVID-19 quarantine. Acta Paediatr. 2020;109(10):2147-2148. DOI: 10.1111/apa.15420

8. Ghosh R, Dubey MJ, Chatterjee S, Dubey S. Impact of COVID-19 on children: Special focus on psychosocial aspect. Minerva Pediatr. 2020;31:34. DOI: 10.23736/S0026-4946.20.05887-9

9. Piercy KL, Troiano RP. Physical activity guidelines for Americans from the US department of health and human services: Cardiovascular benefits and recommendations. Circ Cardiovasc Qual Outcomes. 2018;11(11):e005263. DOI: 10.1161/CIRCOUTCOMES.118.005263

10. Bull FC, Al-Ansari SS, Biddle S, et al. World Health Organization 2020 guidelines on physical activity and sedentary behaviour. $B r \quad J$ Sports Med. 2020;54(24):1451-1462. DOI: 10.1136/bjsports-2020-102955

11. Aubert S, Barnes JD, Abdeta C, et al. Global matrix 3.0 physical activity report card grades for children and youth: results and analysis from 49 countries. J Phys Act Heal. 2018;15(s2):S251S273. DOI: 10.1123/jpah.2018-0472

12. Tison GH, Avram R, Kuhar P, et al. Worldwide effect of COVID-19 on physical activity: a descriptive study. Ann Intern Med. 2020;3(173(9)):767-770. DOI: 10.7326/M20-2665

13. Guan H, Okely AD, Aguilar-Farias N, et al. Promoting healthy movement behaviours among children during the COVID-19 pandemic. Lancet Child Adolesc Heal. 2020;4(6):416-418. DOI: 10.1016/S2352-4642(20)30131-0

14. Xiang M, Zhang Z, Kuwahara K. Impact of COVID-19 pandemic on children and adolescents' lifestyle behavior larger than expected. Prog Cardiovasc Dis. 2020;63((4)):531-532. DOI: 10.1016/j.pcad.2020.04.013

15. Brooks JHM, Tingay R, Varney J. Social distancing and COVID-19: an unprecedented active transport public health opportunity. Br J Sport Med. 2020;7:2020-102856. DOI: 10.1136/bjsports2020-102856

16. Budd L, Ison S. Responsible Transport: A post-COVID agenda for transport policy and practice. Transp Res Interdiscip Perspect. 2020;6:100151. DOI: 10.1016/j.trip.2020.100151

17. Larouche R, Saunders TJ, Faulkner GEJ, Colley R, Tremblay M. Associations between active school transport and physical activity, body composition, and cardiovascular fitness: a systematic review of 68 studies. J Phys Act Heal. 2014;11(1):206-227. DOI: 10.1123/jpah.2011-0345

18. Viner RM, Russell SJ, Croker H, et al. School closure and management practices during coronavirus outbreaks including COVID-19: a rapid systematic review. Lancet Child Adolesc Heal. 2020;4(5):397-404. DOI: 10.1016/S2352-4642(20)30095-X

19. WHO. Coronavirus disease (COVID-19): Schools | Q\&A. World Health Organization. Published 2020. Accessed November 18，2020. https:/www.who.int/news-room/q-a-detail/coronavirusdisease-covid-19-schools

\section{Affiliations}

${ }^{1}$ PROFITH "PROmoting FITness and Health Through Physical Activity" Research Group, Department of Physical Education and Sports, Faculty of Sport Sciences, Sport and Health University Research Institute (iMUDS), University of Granada, 18071 Granada, Spain; imponator@correo.ugr.es.

2 PROFITH "PROmoting FITness and Health Through Physical Activity" Research Group, Department of Physical Education and Sports, Faculty of Education and Sport Sciences, Sport and Health University Research Institute (iMUDS), University of Granada, 52071 Melilla, Spain. 


\section{Author Contributions:}

EV-G, YB-R jointly conceived of the idea. PC critically reviewed the manuscript and all authors contributed to editing and refining the final draft. All authors read and approved the final manuscript.

\section{Declaration of conflict of interest}

The authors declare no conflict of interest.

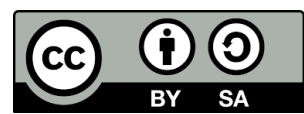

Copyright (c) 2022 Journal of Movement and Health. This document is published with the Open Access policy. Distributed under the terms and conditions of Creative Commons 4.0 International. https://creativecommons.org/licenses/by-sa/4.0/. 